\author{
Małgorzata Kurianowicz \\ Biatystok
}

\title{
Realizacja jerów w cerkiewnosłowiańskich, ewangelicznych tekstach drukowanych*
}

Słowa kluczowe: jery, język cerkiewnosłowiański ruskiej redakcji, starodruki ewangeliczne

Przedmiotem niniejszej analizy porównawczej są zapisy półsamogłosek, zarejestrowanych $\mathrm{w}$ tekście wyekscerpowanych $\mathrm{z}$ dwóch cerkiewnosłowiańskich starodruków ewangelicznych. Poddane analizie zabytki powstały na przestrzeni 200 lat i należą do jednej, ruskiej redakcji. Pierwszy z nich to Biblia Ostrogska 1581 r. (dalej: BO) z terenu państwa polsko-litewskiego [mikrofilm Biblioteki Uniwersytetu Warszawskiego 16235 na podstawie egzemplarza o sygn. 612.105] - jedno z najwcześniejszych drukowanych wydań wszystkich ksiąg Pisma Świętego, a drugi - synodalny Ewangeliarz Jabłeczyński 1771 r. (dalej: EJ), który wyszedł spod druku mnichów Kijowsko-Pieczerskiej Ławry, a znajdujący się obecnie w stauropigialnym Prawosławnym Klasztorze św. Onufrego w Jabłecznej (woj. lubelskie).

Zasadniczo w BO i EJ spotykamy się z typowym dla języka staroruskiego rozwojem jerów, tj. ich wokalizacją, gdy znajdowały się w pozycji silnej i redukcją, gdy stały w pozycji słabej (XII-XIII w.) [Moszyński, 219-220]. Oddzielną grupę stanowią formacje, w których pisownia jerów została zachowana czy to w śródgłosie, czy w wygłosie. Poniższy materiał egzemplifi-

\footnotetext{
* Niniejsza publikacja powstała ze środków MNiSW na naukę, w ramach grantu promotorskiego nr NN104 0577438 pt. Biblia Ostrogska i XVIII-wieczna Ewangelia klasztoru w Jablecznej - cerkiewnostowiańskie zabytki redakcji ruskiej.

1 Historię powstania BO przedstawia m.in. Я. Д. Исаевич [Исаевич, 3-17], Е. Л. Немировский, [Немировский, 89-166].
} 
kacyjny stanowi wybór półsamogłosek z odzwierciedlonym procesem wokalizacji lub zaniku w zależności od pozycji w wyrazie ${ }^{2}$, a wyekscerpowanych z czterech tekstów ewangelicznych (Mt, Mk, Łk, J), por.:

${ }^{*} \underline{\mathbf{z}}>\varnothing$ SOлъ (Mt 5:11), совравъ (Mt 2:4), сотвори (Mk 5:19), сонмнце (Mk 1:21), востани (Mt 9:6), во старости (Łk 1:36), сынома(Mt 20:20), вопмь (Mt 2:18), домомъ (Mt 24:45), страхомъ (Łk 2:9), возми (Mt 17:27);

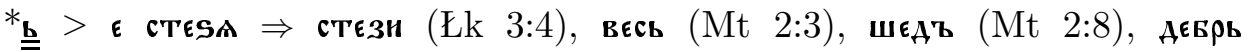
(玄k 3:5), Анцемъ (Łk 1:76), двєрємъ (Mk 1:33), запов тємъ (Mt 2:12), врачємъ $\Rightarrow$ врачемъ (Łk 8:43), правєАєнъ (J 6:30), вШєАЪ (Mk 11:15), вЊнєцъ (J 19:2), внҺшнєе (Mt 23:26);

* $\underline{\mathbf{z}}>\varnothing$ никтоже (Mk 2:21), мною (Mt 4:10), много (Mk 1:45), мн't (Mk 8:34), Ачи (Mk 5:35), притча (Łk 8:4), два (J 4:40), гА $\mathbf{k}(\mathrm{J} 1: 39)$, зАравы (Mt 15:30), разбнваєтъ (Mk 9:18), вшєАъ (Mk 11:15), вннде (J 20:6); * $>$ > что (Mk 14:4), пшєница (Mt 13:29), вышнаго $\Rightarrow$ вышнагш (Łk 1:32), днесь (Łk 4:21), все (J 6:37), всєю (Mk 12:30), возми (Mt 17:27), мЗАы (Mk 9:41), правєдна (Łk 1:6), сањпца $\Rightarrow$ сањпца (Mt 9:28).

Wokalizacja jerów w silnej pozycji cechuje język zarówno BO, jak i EJ. Wahania dotyczą zasadniczo wokalizacji ъ $>0$ w prefiksach $\mathbf{c} \mathbf{b}-$, $\mathbf{B} \mathbf{b}-$, въ33-, въc-. W miejscu, gdzie w XVIII-wiecznym tekście liturgicznym zostało odzwierciedlone typowe dla języków ruskich zjawisko przejścia $\mathbf{b}>\mathbf{0}$, język BO z dużą konsekwencją rejestruje archaiczne zapisy z półsamogłoskami tylnymi, przypominającymi o starej tradycji, nawiązując w ten sposób swoją pisownią do staro-cerkiewno-słowiańskich zabytków, por.: сътворю $\Rightarrow$ coтворю (Mt 19:16), съвлазнимъ $\Rightarrow$ совлазнимъ (Mt 17:27), съБрасл $\Rightarrow$ соБраса (Mk $3: 20)$, въпросити $\Rightarrow$ вопросити (J 13:24), вънстинн४ $\Rightarrow$ вонстинну (Mt 27:54), въста $\Rightarrow$ воста (Łk 24:6), въ3Аано $\Rightarrow$ в0зАано (J 11:41), възАвигн8 $\Rightarrow$ воздвигнУ (J 2:19), въспрїатъъ $\Rightarrow$ воспрїАттъ (Łk 1:54), въьтокъ $\Rightarrow$ востшкъ (Mt 2:1). Na uwagę zasługują formy staro-cerkiewno-słowiańskiego czasownika съврьшати, których prefiks jako jedyny w EJ przybrał zarówno formę co (16 u., 81\%), por.: съвершихъ $\Rightarrow$ соверших'ъ (J 17:4), съвєр-

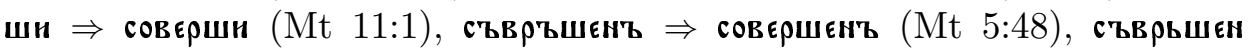
$\Rightarrow$ совєршєн (Mt 19:21), jak i postać bezjerową (3 u., 19\%), por.: съвєршєни $\Rightarrow$ свершени (J 17:23), съврьшияъ $\Rightarrow$ свершияъ (Mt 21:16), съврьшаюТтЪ $\Rightarrow$ свєршаютъ (Łk 8:14). Zjawisko opuszczenia jeru tylnego ъ $\mathrm{w}$ prefiksie $\mathbf{c} \mathbf{b}$ czasowników jest szeroko udokumentowane w wielu zabytkach staro-cerkiewno-słowiańskiego kanonu oraz w najstarszych staroruskich przekładach,

2 Linią podwójną (_ zaznaczone zostały jery w pozycji silnej, a pojedynczą (_) - w pozycji słabej. W przypadku, gdy zapis leksemu jest różny w obu tekstach, materiał egzemplifikacyjny przytaczany jest w kolejności $\mathrm{BO} \Rightarrow$ EJ. 
jednak zazwyczaj dotyczy ono derywatów werbalnych сътворити [Perczyńska, 58]. Pojawienie się w EJ zapisów z ominięciem jeru tylnego z w prefiksie cъ można potraktować jako nawiązanie do tradycji kanonu, ewentualnie, ze względu na niewielką frekwencję, jako redaktorskie przeoczenie.

Udokumentowane w XVI-wiecznej BO zapisy z wokalizacja jeru tylne-

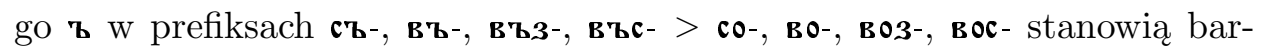
dzo nieliczną grupę, por.: сотвори (Mk 5:19), создати (Łk 14:28), возм8-

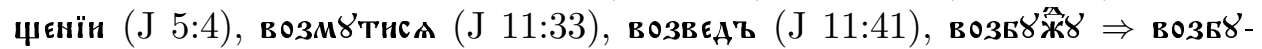
ж४ (J 11:11), воскрєсєнїє (J 11:25). Konsekwentne odzwierciedlenie zjawiska przejścia $\mathbf{z}>0 \mathrm{w}$ powyższych prefiksach rejestrują zabytki pochodzące dopiero z XVII w., w tym przedrukowany tekst BO - cerkiewnosłowiańska Biblia Moskiewska (1663 r.) [Булич, 140].

Analiza porównawcza wykazała, iż ewangeliczne teksty nie zachowują jednolitości w zapisie jerów w śródgłosowych grupach ${ }^{*} l_{b} s t,{ }^{*} l_{b} n$ oraz ${ }^{*} n b s k$, w których jer przedni s oznaczał miękkość poprzedniej spółgłoski. Język BO rejestruje zarówno pisownię *nbsk (9 u. od 6 h.), jak i *nsk (19 u. od 8 h.), podczas gdy EJ konsekwentnie odzwierciedla zapis *nsk $\mathrm{z}$ twardym $n$ charakterystycznym dla języka rosyjskiego, por.: єлминьскоє $\Rightarrow$ ємминскоє (J 7:35), вавчнаоньскаго $\Rightarrow$ вавунашнскагш (Mt 1:17), горУ єлєоньскУ $\Rightarrow$ горУ елєшнскУ (J 8:1), женьскї̈ $\Rightarrow$ жєнскїй (Mt 19:4), сндоньска $\Rightarrow$ сндшнска (Łk 6:17) oraz гадаринск४ю (Łk 8:26), самаранск४ (Łk 9:52), гергесинск४ю (Mt 8:28). Gdy porównamy statystyczne użycia tych grup w BO, to ilościową przewage posiadają formacje z grupa * ${ }^{*} s k(68 \%)$. Jednak, gdy zestawimy liczbę haseł, to okaże się, iż grupę z palatalną spółgłoską $n$ rejestruje już tylko połowa wszystkich haseł $\left({ }^{*} n b s k-43 \%,{ }^{*} n s k-57 \%\right)$. Jak wskazują badania przeprowadzone przez Z. Stiebera, miękkość spółgłoski $n$ w języku staroruskim była dobrze zachowana jeszcze $\mathrm{w}$ XIV w. Proces jej dyspalatalizacji zakończył się na początku w XVI w. [Stieber, 3-17]. Stąd wniosek, iż twarda grupa *nsk w EJ i BO jest naturalnym odzwierciedleniem żywej wymowy, a udokumentowana konsekwencja zapisów w XVIII-wiecznym starodruku świadczy o ukształtowaniu się dla młodszych tekstów cerkiewnosłowiańskich ruskiej redakcji nowej ortograficznej normy.

Z kolei grupa *lbn w obu starodrukach bezwyjątkowo przybrała postać *ln wskazującą na graficzne ,stwardnienie” spółgłoski l, por.: свłтил-

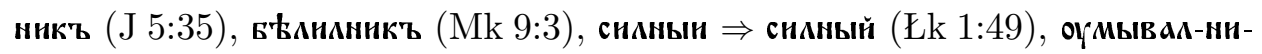
ц8 (J 13:5), витахннца (Mk 14:14), каднанаго (Łk 1:11), волна (Mt 25:44), доволно (Łk 22:38), селныХъ (Mt 6:28), скУАєлннчє (Mt 27:7), погиБєАнын (J 17:12). Z. Stieber powód graficznego „stwardnienia” $l$ w połączeniu *lbn upatruje w zmniejszonym stopniu palatalności $l$ przed spółgłoskami 
np. w grupie $l s k, l s t, l c, l \check{c}^{3}$, nawet tam, gdzie nie odbijało to rzeczywistej wymowy. С. Булич również jako przyczynę wskazuje zmniejszenie stopnia miękkości spółgłoski $l$ :

палатальность $\Omega$ ' казалась такой ничтожной звуковой разницей, что обозначение ея представлялось излишним [Булич, 138].

Natomiast w kwestii zapisu grupy *lbst język obu tekstów wykazuje znaczące wahania $\left({ }^{*} l b s t,{ }^{*} l s t\right)$, przy czym frekwencja użyć z jerem przednim typu * lbst w BO jest znacząco większa w porównaniu z tekstem EJ i wynosi odpowiednio $84 \%$ i $13 \%$ (w BO - 77 u. od 5 h. a w EJ - 10 u. od 4 h.),

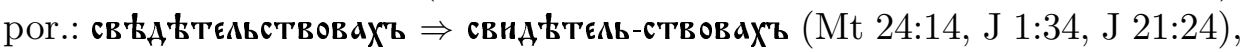

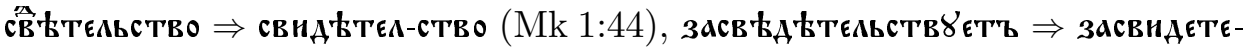

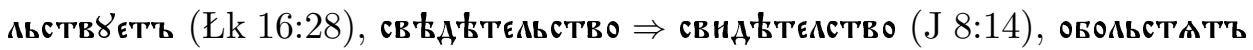
$\Rightarrow$ ШБОАСТАТТ (Mk 12:13), НачААьСТвУ (Łk 20:20), прєАьститъ (Mk 13:5), Аьстит $\Rightarrow$ Аьститъ $(J 7: 12)$, Аьсти $\Rightarrow$ Асти $(\mathrm{J} 1: 47)$, АьстєЦъ $\Rightarrow$ АстеЦъ (Mt 27:63).

Podsumowując, przeprowadzona analiza realizacji jerów w prasłow. grupach ${ }^{*} l b s t,{ }^{*} l b n$ oraz ${ }^{*} n b s k$ wykazała, że młodszy język EJ w większym stopniu, niż BO odzwierciedla tendencję do opuszczania w pisowni etymologicznego jeru miękkiego s w pozycjach, gdzie często nie oddawało to rzeczywistej artykulacji.

Nieuregulowana ortografia w oznaczaniu miękkości poprzedzającej spółgłoski jest też przyczyną pojawienia się w obu tekstach takich rozbieżnych zapisów, jak волша $\Rightarrow$ Больша (J 1:50), вонжє $\Rightarrow$ воньже (J 5:28), дОНьдєЖе $\Rightarrow$ АОНАЕЖЕ (Mt 5:26), АОНЪАЕЖЕ $\Rightarrow$ АОНАЕЖЕ (J 9:4), стрАСТЬМИ $\Rightarrow$ стрАСТМИ (Mt 4:24).

Szczególnego omówienia wymaga użycie tzw. jerów wtórnych ${ }^{4}$. Pozycja, która sprzyjała ich zachowaniu w obu starodrukach - to wygłos. Język EJ nie dokumentuje ani jednego poświadczenia, w którym ta ortograficzna zasada nie byłaby utrzymana (nie uwzględniono tu formacji przenoszonych do następnego wiersza, por. niżej). Zgoła inaczej zapis jerów wygłosie zilustrowany został w tekście BO. Stosunkowo łatwa do zapamiętania norma w XVI-wiecznym starodruku posiada wiele odchyleń, por.: Gомомон $\Rightarrow$ Gомо-

3 Na skutek częściowej, czysto fonetycznej depalatalizacji l, spółgłoska w pozycji lsk stała się mniej palatalna niż np. w wyrazie nолє. Ta różnica między dwoma pozycyjnymi wariantami fonemu $l$ została zaznaczona przez opuszczenie jeru przedniego $b$ przed $s k$ [Stieber, 3-17].

4 O pojawieniu się jeru wtórnego decydowały trzy reguły ortograficzne: 1) każdy wyraz powinien być zakończony samogłoską, ewentualnie półsamogłoską (jerem), 2) samogłoska lub jer powinien zwieńczać wiersz tekstu 3) prefiks powinien być oddzielony jerem od pozostałej części wyrazu [Friedelówna, 79; Воробьёва, 42]. 
мшнъ (Mt 1:7), Зоровавєа $\Rightarrow$ Зоровавеаь (Mt 1:13), Ісаак $\Rightarrow$ Iсаакъ (Mt 1:1), Фзор $\Rightarrow$ Фзшръ (Mt 1:14), потом жє $\Rightarrow$ потомъ жє (J 13:5), в сєБ' $\Rightarrow$ въ сєь' (J 13:32), с ннмъ $\Rightarrow$ съ нимъ (Mk 5:24), н3 $\Rightarrow$ н3ъ $(\mathrm{J} 20: 9)$, ис $\Rightarrow$ изъ

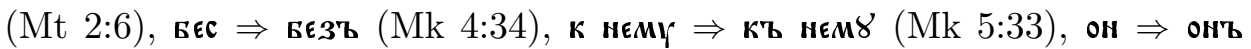
(Mt 4:4), вндєв $\Rightarrow$ внд $\mathbf{k в ъ}$ (Mt 3:7, Łk 23:47). Zapisy z ominięciem jeru wygłosowego, będące odzwierciedleniem żywych tendencji językowych, dotyczą różnych części mowy, w szczególności przyimków oraz zapożyczonych imion własnych. Opuszczenie półsamogłoski w BO jest przypadkowe i nie nosi znamion jakiejkolwiek reguły, co świadczy przede wszystkim o nieustabilizowanej ortografii.

W obu starodrukach nie została utrzymana ortograficzna zasada wymagająca w sytuacji przenoszenia wyrazu do nowego wiersza kończenia sylaby elementem wokalicznym, a więc przynajmniej jerem [Friedelówna, 107]. W BO przeważająca większość (86\%) przenoszonych formacji za-

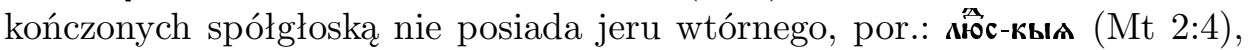

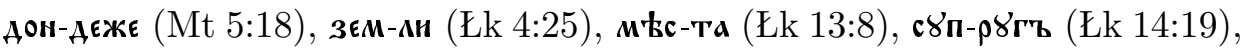
ос-мын (Łk 1:59), сил-нын (Łk 1:49), ол-тарл (Łk 1:11); ЕJ: жит-ницы (Łk 12:18), Арєв-нихъ (Łk 9:19), одєЖ-дахъ (Łk 20:36), шчнс-тити (Mk 1:40), въ тєм-ннц' ( $\mathrm{Mk} \mathrm{6:17),} \mathrm{вєч-ный} \mathrm{(J} \mathrm{4:14),} \mathrm{возрадуєт-сл} \mathrm{(J} \mathrm{16:20).} \mathrm{Język}$ tekstów ewangelicznych BO poświadcza tylko cztery zapisy przypominające о istnieniu dawnej ortograficznej zasady, por.: ВО: донъ-дєжє (Łk 13:8),

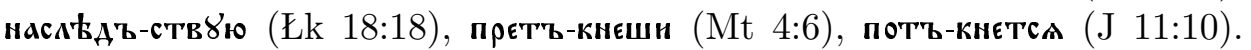
Tekst EJ nie rejestruje ani jednego przykładu przenoszonego wyrazu z jerem wtórnym, co świadczy o zaniku w XVIII w. tej starej, ortograficznej normy.

Jeru wtórnego nie rejestrują również starodruki w położeniu między prefiksem a pozostałą częścią wyrazu (trzecia norma ortograficzna). Wszystkie zapisy dokumentują jego regularną redukcję, por.: въспрїатъ $\Rightarrow$ воспрїлттъ (Łk 1:54), възгАасити $\Rightarrow$ возгАасити (Mk 10:49), изрєчє (Mt 14:7), раздє-

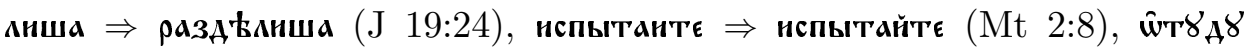
$\Rightarrow$ wTr $_{A} \boldsymbol{\gamma}(\mathrm{Mk} 6: 1)$.

Z przeprowadzonej analizy wynika, iż w zakresie zapisu samogłosek jerowych język BO i EJ wykazuje dużą zgodność z regułą rozwojową właściwą ruszczyźnie - wokalizacją, gdy znajdowały się one w pozycji silnej oraz zanikiem, gdy stały w pozycji słabej. Jednak pomimo przynależności obu tekstów do jednej, ruskiej redakcji piśmienniczej, ich realizacja nie zawsze pozostawała jednakowa - wahania dotyczą w szczególności prefiksów ç-, Bъ-, въ3-, въc-, zapisu śródgłosowych grup *lbst, ${ }^{*} l_{b} n$ oraz $* n b s k$ oraz zapisu jerów wtórnych, będących odzwierciedleniem tendencji zachodzących w żywym języku. 


\title{
Literatura
}

Friedelówna T., 1974, Ewangeliarz Eawryszewski. Monografia zabytku, Wrocław-Warszawa-Kraków-Gdańsk.

Moszyński L., 2006, Wstęp do filologii słowiańskiej, Warszawa.

Perczyńska B., 2007, Język najstarszych ruskich zabytków hagiograficznych. Fonetyka. Fleksja imienna $i$ werbalna, Lublin.

Stieber Z., 1980, Procesy pozycyjnego twardnienia spółgłosek palatalnych w historii jezyka rosyjskiego, "Rocznik Slawistyczny” T. XL, cz. I, s. 3-17.

Булич С., 1893, Церковнославянские элементы в современном литературном и народном русском языке, ч. 1, Санкт-Петербург.

Воробьёва А. Г., 2008, Учебник иерковнославянского языка, Москва.

Исаевич Я. Д., 1990, История издания Острожской библии, [w:] Острожская Библия. Сборник статей, Москва, с. 3-17.

Немировский Е. Л., 2005, Острожская Библия, [w:] Федоровские чтения, Москва, с. 89-166.

\section{YERS IN CHURCH SLAVONIC PRINTED EVANGELICAL TEXTS}

\author{
S U M M A R Y
}

The article deals with the problem of the yers reflected in two Church Slavonic printed Gospels: the first completed printed edition of the Church Slavonic Bible The Ostrog Bible (1581) and the18th century altar Gospel (1771) printed in Kiev Pechersk Lavra but kept in Orthodox monastery in Jabłeczna (south-east Poland).

The analysis has shown, that BO and EJ present some compatibility typical for the Ruthenian languages - yers strong position vocalization and weak position reduction. However, despite being part of one Ruthenian Recension, yers reflection in both texts was not always the same - the biggest differences were noticed in cra-, въ-, въ3-, въc- prefixes, combinations such as $* l_{b s t},{ }^{*} l_{b} n,{ }^{*} n b s k$ and secondary yers records.

m.kurianowicz@uwb.edu.pl 